\title{
Effect of pericardial incision on left ventricular morphology and systolic function in patients during coronary artery bypass grafting
}

Lan-Ting Zhao ${ }^{1}$, Lu Liư ${ }^{2}$, Ping-Ping Meng ${ }^{1}$, Yong-Huai Wang ${ }^{1}$, Meng Li ${ }^{1}$, Jun Yang ${ }^{1}$, Tian-Xiang Gu ${ }^{2 *}$ and Chun-Yan $\mathrm{Ma}^{1 *}$ (D)

\begin{abstract}
Background: Accurate assessment of left ventricular (LV) systolic function is important after coronary artery bypass grafting (CABG). LV ejection fraction (LVEF) is conventionally used to evaluate LV systolic function; deformation parameters can be used to detect subtle LV systolic dysfunction. It is unclear whether an incised pericardium without sutures during CABG could affect LV morphology and function. We investigated the effect of pericardial incision on LV morphology and systolic function during CABG.
\end{abstract}

Methods: Intraoperative transesophageal echocardiography was performed in 27 patients during elective off-pump beating heart CABG 5 min before and after pericardial incision. LV longitudinal and mid-cavity transversal diameters, sphericity index, volumes, and LVEF were measured. LV global longitudinal strain (GLS), global circumferential strain (GCS), global radial strain (GRS), and twist obtained by two-dimensional speckle tracking echocardiography were measured simultaneously.

Results: LV mid-cavity transversal diameter increased, while the LV sphericity index decreased $(P<0.001)$ immediately after pericardial incision. The GLS, GCS, and twist significantly decreased, while the GRS notably increased $(P<0.001)$.

The LV volumes and LVEF remained unchanged.

Conclusions: Pericardial incision immediately transformed LV morphology from an ellipsoid to sphere, with decreased longitudinal and circumferential strain and twist, and increased radial strain, while LVEF remained unchanged. This should be considered when evaluating LV systolic function in patients after CABG.

Keywords: Coronary artery bypass grafting, Pericardial incision, Morphology, Global longitudinal strain

\footnotetext{
*Correspondence: cmugtx@sina.com; cmu1h_mcy@126.com

${ }^{2}$ Department of Cardiac Surgery, The First Hospital of China Medical

University, No. 155 Nanjingbei Street, Heping District, Shenyang 11001, Liaoning, China

'Department of Cardiovascular Ultrasound, The First Hospital of China Medical University, No. 155 Nanjingbei Street, Heping District, Shenyang 11001, Liaoning, China
}

(c) The Author(s). 2020 Open Access This article is licensed under a Creative Commons Attribution 4.0 International License, which permits use, sharing, adaptation, distribution and reproduction in any medium or format, as long as you give appropriate credit to the original author(s) and the source, provide a link to the Creative Commons licence, and indicate if changes were made. The images or other third party material in this article are included in the article's Creative Commons licence, unless indicated otherwise in a credit line to the material. If material is not included in the article's Creative Commons licence and your intended use is not permitted by statutory regulation or exceeds the permitted use, you will need to obtain permission directly from the copyright holder. To view a copy of this licence, visit http://creativecommons.org/licenses/by/4.0/ The Creative Commons Public Domain Dedication waiver (http://creativecommons.org/publicdomain/zero/1.0/) applies to the data made available in this article, unless otherwise stated in a credit line to the data. 


\section{Background}

As a coronary artery revascularization therapeutic strategy, coronary artery bypass grafting (CABG) can effectively improve the myocardial blood supply for complex coronary artery disease. Echocardiography is an optimal, noninvasive method for precisely evaluating left ventricular (LV) systolic function, which has an important role in estimating the therapeutic effect in patients after CABG.

LV ejection fraction (LVEF) is conventionally used as a marker of LV systolic function. Deformation parameters obtained by two-dimensional speckle tracking echocardiography (2D STE) can sensitively detect subtle LV dysfunction at an early stage, LV global longitudinal strain (GLS), in particular, appears to be a more robust parameter and has incremental value in patients referred for cardiac surgery including CABG [1-6].

The pericardium is often incised during CABG without sutures after the surgery, which may affect ventricular morphology and systolic function. Unsworth et al. [7] reported that pericardial incision induced a reduction in right ventricular (RV) systolic function in 9 patients who underwent CABG; however, it is still unclear whether it can affect LV systolic function. Therefore, we sought to investigate the effect of pericardial incision on LV morphology and systolic function during CABG using intraoperative transesophageal echocardiography (TEE).

\section{Methods}

\section{Study population}

Patients who underwent elective off-pump beating heart CABG between January 2019 and June 2019 in our hospital were consecutive recruited for this study. Patients were excluded if they had a prior history of cardiac surgery, a combination of other cardiac surgery, pericardial disease, arrhythmia, or contraindication to TEE. All patients underwent coronary angiography before CABG and their results were assessed by experienced cardiologist. The SYNTAX score was calculated using the SYNT AX score algorithm (www.syntaxscore.com) [8]. All procedures performed in the studies involving human participants were in accordance with the ethical standards of the Ethics Committee of the China Medical University. Informed consent was obtained from all individual participants included in the study.

\section{Intraoperative echocardiographic image acquisition}

After induction of anesthesia, an intraoperative TEE examination was performed 5 min before and after pericardial incision during the surgery using the CX50 ultrasound system (Philips Healthcare, Andover, MA, USA) equipped with an X7-2t transducer. The TEE probe was inserted into the patient's esophagus to obtain midesophageal 4-chamber (ME 4C), 2-chamber (ME 2C), and long-axis (ME LAX) views, and into the patient's stomach to obtain transgastric basal, mid-papillary, and apical short-axis views. The basal level was identified by the mitral valve, and the apical level was defined as proximal to the level with ventricular cavity obliteration at end-systole. All manipulations of image acquisition were performed according to the recommendations from the American Society of Echocardiography [9]. Standard two-dimensional cine loops, including at least 3 consecutive cardiac cycles with frequency of 50-70 frames per second, and Doppler spectrum were stored in cineloop format.

\section{Echocardiographic image measurements and analyses}

All data were transferred to a workstation for further offline analysis using the Qlab software package (Philips Healthcare). LV longitudinal and mid-cavity transversal diameters were measured at end-diastole in ME $4 \mathrm{C}$ view, and the LV sphericity index (LVSI) was defined as the ratio of the LV longitudinal to mid-cavity transversal diameter [10]. The LV internal diameter and posterior wall thickness were measured at end-diastole in transgastric mid-papillary short-axis view, and the relative wall thickness was calculated simultaneously [9]. The LV end-diastolic volume, end-systolic volume, stroke volume, and LVEF were measured using the biplane modified Simpson's method with ME $4 \mathrm{C}$ and ME $2 \mathrm{C}$ views. Mitral inflow early (mitral E) and late (mitral A) diastolic velocity, mitral annular septal and lateral early diastolic velocity (septal e' and lateral e'), and tricuspid regurgitation velocity were measured in the ME $4 \mathrm{C}$ view. Then mitral E/A, and mitral average E/e' were calculated.

Deformation parameters, including LV GLS, global circumferential (GCS), and global radial strain (GRS), were measured using 2D STE. Endocardial contour was manually adjusted to optimize tracking when necessary, and patients with inadequate tracking, which was defined by the mismatch between the region of interest and the myocardium during dynamic loops, of more than two segments were excluded from the study. The degree of LV peak systolic apical and basal rotation was measured at the apical and basal levels, respectively. Twist was defined as the net difference between apical and basal rotation. The absolute change rates of LV GLS, GCS, GRS, twist, and LVSI were calculated as the percentage of the difference in these parameters before and after pericardial incision divided by that before pericardial incision. A significant reduction of GLS was defined as a decrease of GLS by $>15 \%$ immediately after pericardial incision [11].

The RV basal, mid-cavity transversal, and longitudinal diameters were measured at end-diastole in $\mathrm{ME} 4 \mathrm{C}$ view, and the RV sphericity index was defined as the ratio of the RV longitudinal to mid-cavity transversal diameter 
[10]. The RV end-diastolic and end-systolic areas were measured in $\mathrm{ME} 4 \mathrm{C}$ view, and the $\mathrm{RV}$ fractional area change was calculated simultaneously [1].

\section{Hemodynamic measurements}

Hemodynamic monitors were supplemented by radial arterial and central venous catheters. Hemodynamic parameters including systolic blood pressure (SBP), diastolic blood pressure (DBP), mean arterial blood pressure (MAP), central venous pressure (CVP), and heart rate $(\mathrm{HR})$ were recorded simultaneously at the time of image acquisition.

\section{Reproducibility}

Intra- and inter-observer agreement for global strain and rotation were examined in 10 randomly selected patients. The same observer, who was blinded to the initial measurements, repeated the measurements to assess intra-observer agreement after more than 4 weeks had elapsed. And another independent observer repeated the measurements twice to assess inter-observer agreement.

\section{Statistical analysis}

Statistical analyses were performed using SPSS 25.0 (IBM Corp., Armonk, NY, USA). Normality plots with tests were performed using the Shapiro-Wilk test. Categorical data are presented as frequencies and percentages, normally distributed data as mean $\pm \mathrm{SD}$, and nonnormally distributed data as median and interquartile range. Comparisons of continuous variables before and after pericardial incision were made using the paired Student t-test or Wilcoxon test, as appropriate. Comparisons of SYNTAX score between patients with and without reduction of GLS by $>15 \%$ were made using the independent Student $t$-test. The Pearson coefficient was used for correlation analysis. The relationship between

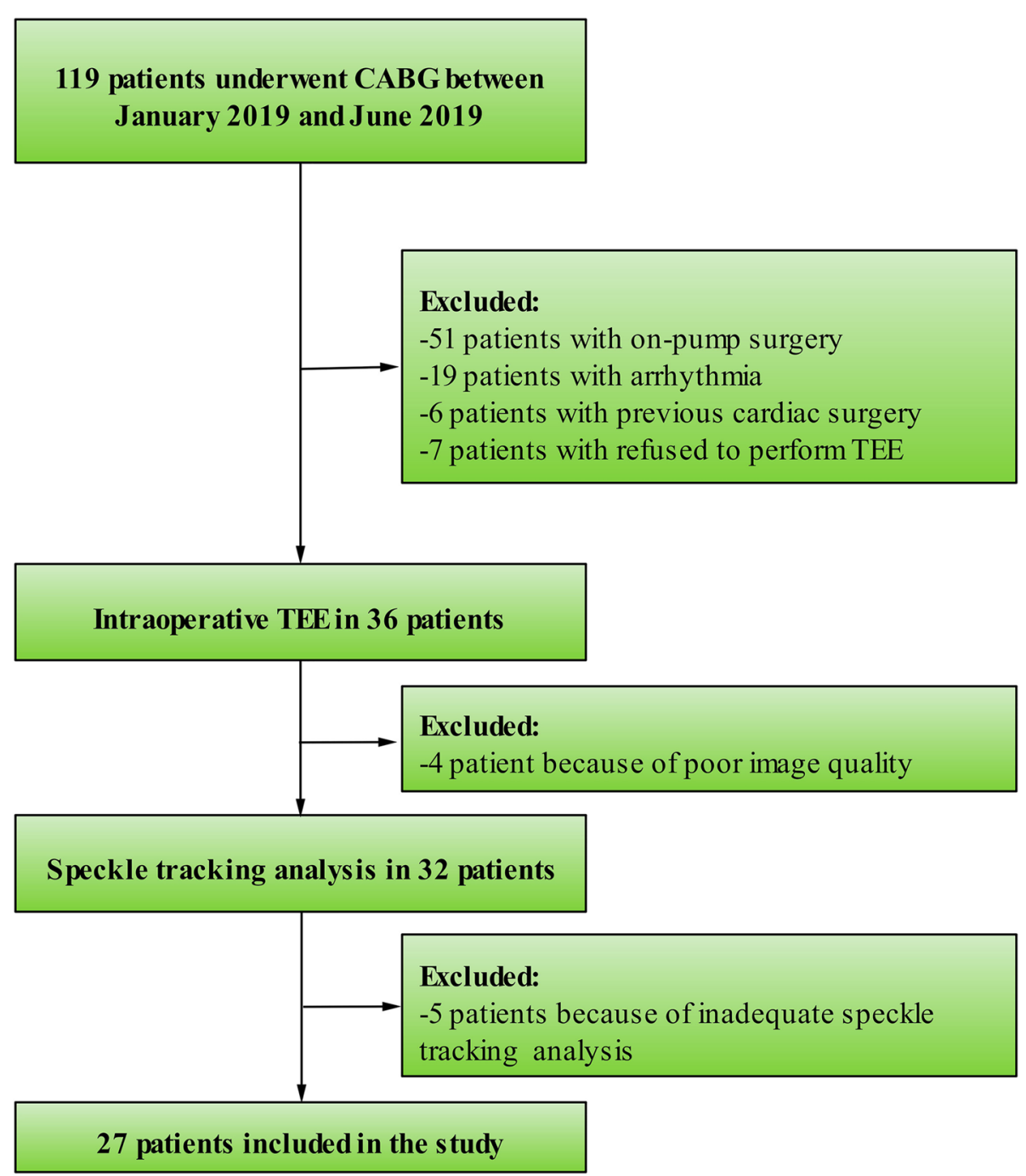

Fig. 1 Patient flow chart 
the change rate of GLS and continuous variables was analyzed using simple linear regression analysis. Intraobserver and inter-observer agreement analyses of global strain and rotation were assessed using Bland-Altman analysis in 10 randomly selected patients. A $P$-value < 0.05 was considered significant.

\section{Results}

\section{Baseline characteristics}

A total of 36 patients performed the intraoperative TEE. Among these patients, 4 patients were excluded because the standard transgastric short-axis view with optimal image quality were unable to be acquired, and 5 patients were excluded due to the inadequate speckle-tracking analyses from apical views $(n=1)$ and transgastric shortaxis views $(n=4)$. Finally, 27 patients $(18$ men; mean age, $61.2 \pm 6.7$ years) were enrolled in the analyses (Fig. 1). During the perioperative period, there were 2 patients experienced prolonged mechanical ventilation due to poor cardiopulmonary function. The baseline characteristics of these patients are shown in Table 1.

\section{Hemodynamics measurements before versus after pericardial incision}

Immediately after pericardial incision, there was no significant change in CVP, SBP, DBP, MAP, and HR (Table 2).

\section{LV morphology and function before versus after pericardial incision}

The LV mid-cavity transversal diameter increased $(P<$ $0.001)$, while the LV sphericity index significantly decreased immediately after pericardial incision $(P<0.001)$, and the posterior and relative wall thicknesses increased $(P<0.05$, Table 3$)$. There were no significant differences in mitral E, A, E/A, septal e', lateral e' and mitral average $\mathrm{E} / \mathrm{e}^{\prime}$, and tricuspid regurgitation velocity between before and after pericardial incision (Table 3).

In the 27 patients, there were $16(9.9 \%)$ views were manually adjusted to optimize the tracking of LV myocardium. After pericardial incision, LV GLS and GCS decreased, and the GRS increased simultaneously $(P<$ 0.001), while the LV volumes and LVEF remained unchanged. Meanwhile, the reduction of LV twist was accompanied by decreased apical and basal rotation $(P<$ 0.001, Table 3 and Fig. 2). Furthermore, the change rate of GRS was correlated with the change rate of GCS $(r=$ $0.44, P=0.02$ ), and the change rate of GLS was significantly and inversely correlation with the SYNTAX score $(r=-0.63, P<0.001)$.

Seventeen patients had a significant reduction of GLS by $>15 \%$ immediately after pericardial opening, and the SYNTAX score was lower in these patients than in the
Table 1 Patient baseline characteristics

\begin{tabular}{|c|c|}
\hline Variable & Value $(n=27)$ \\
\hline Age (y) & $61.2 \pm 6.7$ \\
\hline Male sex & $18(66.7 \%)$ \\
\hline Body mass index $\left(\mathrm{kg} / \mathrm{m}^{2}\right)$ & $25.76 \pm 3.29$ \\
\hline Smoker & $10(37.0 \%)$ \\
\hline \multicolumn{2}{|l|}{ Medical History } \\
\hline Hypertension & $17(63.0 \%)$ \\
\hline Diabetes mellitus & $8(29.6 \%)$ \\
\hline Previous myocardial infarction & $13(48.1 \%)$ \\
\hline Dyslipidemia & $8(29.6 \%)$ \\
\hline Pulmonary hypertension & $1(3.7 \%)$ \\
\hline Previous $\mathrm{PCl}$ & $4(14.8 \%)$ \\
\hline Peripheral vascular disease & $4(14.8 \%)$ \\
\hline Troponin I level (ng/ml) & $0.01(0.004,0.03)$ \\
\hline $\begin{array}{l}\text { Brain-type natriuretic peptide level } \\
(\mathrm{pg} / \mathrm{ml})\end{array}$ & $49.00(21.00,83.00)$ \\
\hline NYHA class (I/II/III/IV) & $\begin{array}{l}4(14.8 \%) / 17(63 \%) / 6(22.2 \%) / 0 \\
(0 \%)\end{array}$ \\
\hline SYNTAX score & $29.02 \pm 9.53$ \\
\hline Euroscore II & $1.34 \pm 0.64$ \\
\hline \multicolumn{2}{|l|}{ Medications } \\
\hline Aspirin & $18(66.7 \%)$ \\
\hline Beta-blockers & $23(85.2 \%)$ \\
\hline Calcium channel antagonists & $4(14.8 \%)$ \\
\hline Statins & $21(77.8 \%)$ \\
\hline Nitrates & $24(88.9 \%)$ \\
\hline
\end{tabular}

Data are expressed as a mean \pm standard deviation, median (interquartile range) or frequencies (percentages)

Abbreviations: $\mathrm{PCl}$ percutaneous coronary intervention, NYHA New York Heart Association

other 10 patients with nonsignificant variability of GLS $(24.09 \pm 6.03$ versus $37.40 \pm 8.59, P<0.001)$.

\section{$\mathrm{RV}$ morphology and systolic function before versus after pericardial incision}

The RV mid-cavity transversal diameter significantly increased and the RV sphericity index decreased $(P<0.05)$, while the RV fractional area change remained unaltered, which indicated that the right ventricle became more round in shape (Table 4).

Results of the intra-observer and inter-observer agreement analyses of global strain and rotation are presented in Table 5.

\section{Discussion}

In the present study, we found that the pericardial incision can immediately induce the obvious change of LV morphology and contractile pattern. LV morphology changed from an ellipsoid to a sphere, and the relative 
Table 2 Hemodynamic parameters before and after pericardial incision

\begin{tabular}{llll}
\hline Parameter & Before pericardial incision $(n=27)$ & After pericardial incision $(n=27)$ & $P$-value \\
\hline Heart rate $($ beats/min) & $60.67 \pm 14.05$ & $64.56 \pm 10.90$ & 0.15 \\
Central venous pressure $(\mathrm{mmHg})$ & $11.07 \pm 1.88$ & $10.78 \pm 1.28$ & 0.06 \\
Systolic blood pressure $(\mathrm{mmHg})$ & $124.67 \pm 12.89$ & $122.93 \pm 8.83$ & 0.18 \\
Diastolic blood pressure $(\mathrm{mmHg})$ & $69.37 \pm 6.22$ & $68.56 \pm 5.44$ & 0.16 \\
Mean arterial pressure $(\mathrm{mmHg})$ & $87.80 \pm 6.29$ & $86.68 \pm 4.19$ & 0.15 \\
\hline
\end{tabular}

Data are expressed as a mean \pm standard deviation

wall thickness increased immediately after pericardial incision. Additionally, LV deformation parameters markedly changed with a reduced LV global longitudinal and circumferential strain and twist, and an increased global radial strain; however, LV volumes and ejection fraction remained unchanged.

The pericardium maintains the anatomic position of the heart and limits its displacement through ligaments; besides, the relatively inelastic parietal pericardium retracts when it is cut, indicating that it exerts pressure on the underlying myocardial chambers [12-14]. Therefore, pericardial incision may alter the geometry or function of heart during cardiac surgery. Currently, in addition to the patients with CABG, the pericardium is also not sutured after the surgery in the patients with pericardiectomy and inadequate pericardial tissue for suturing, such as adopting autologous pericardial patches in aortic dissection, possible cardiac enlargement due to myocardial edema in complex congenital heart disease or severe valvular heart disease, and so on. Several previous studies have reported a change of RV geometry or reduction of RV systolic function after pericardial incision without suture [7, 15-17], which was similar with our study. Interestingly, the study by Zanobini $M$, et al. [18] also

Table 3 Changes in LV morphology and function before and after pericardial incision

\begin{tabular}{|c|c|c|c|}
\hline Parameter & Before pericardial incision $(n=27)$ & After pericardial incision $(n=27)$ & $P$-value \\
\hline LV longitudinal diameter (mm) & $71.48 \pm 7.48$ & $70.19 \pm 8.00$ & 0.20 \\
\hline LV mid-cavity transversal diameter (mm) & $36.74 \pm 3.99$ & $41.41 \pm 4.59$ & $<0.001$ \\
\hline LV sphericity index & $1.96 \pm 0.26$ & $1.70 \pm 0.19$ & $<0.001$ \\
\hline LV internal diameter (mm) & $44.65 \pm 6.06$ & $45.10 \pm 6.42$ & 0.64 \\
\hline Posterior wall thickness (mm) & $7.59 \pm 1.06$ & $8.13 \pm 0.82$ & 0.007 \\
\hline Relative wall thickness $(\mathrm{cm})$ & $0.34 \pm 0.06$ & $0.37 \pm 0.06$ & 0.04 \\
\hline Mitral E (m/s) & $0.66 \pm 0.20$ & $0.61 \pm 0.18$ & 0.17 \\
\hline Mitral A (m/s) & $0.87 \pm 0.18$ & $0.83 \pm 0.17$ & 0.18 \\
\hline Mitral E/A & $0.81 \pm 0.38$ & $0.77 \pm 0.29$ & 0.47 \\
\hline Septal e' (cm/s) & $6.26 \pm 2.15$ & $6.04 \pm 2.10$ & 0.16 \\
\hline Lateral e' (cm/s) & $7.66 \pm 2.81$ & $7.47 \pm 2.88$ & 0.10 \\
\hline Mitral average E/e' & $10.38 \pm 3.62$ & $10.16 \pm 3.79$ & 0.58 \\
\hline Tricuspid regurgitation velocity $(\mathrm{m} / \mathrm{s})$ & $1.52 \pm 0.61$ & $1.47 \pm 0.59$ & 0.43 \\
\hline LV end-diastolic volume (mL) & $109.48 \pm 35.05$ & $110.33 \pm 35.33$ & 0.25 \\
\hline LV end-systolic volume (mL) & $47.85 \pm 22.12$ & $49.04 \pm 22.58$ & 0.26 \\
\hline LV stroke volume $(\mathrm{mL})$ & $61.63 \pm 15.06$ & $61.30 \pm 15.85$ & 0.74 \\
\hline LVEF (\%) & $57.41 \pm 6.08$ & $56.63 \pm 6.82$ & 0.35 \\
\hline GLS (\%) & $-15.86 \pm 2.66$ & $-12.39 \pm 3.27$ & $<0.001$ \\
\hline GCS (\%) & $-22.25 \pm 4.56$ & $-18.45 \pm 5.07$ & $<0.001$ \\
\hline GRS (\%) & $18.41 \pm 6.05$ & $23.13 \pm 7.32$ & $<0.001$ \\
\hline Apical rotation $\left(^{\circ}\right)$ & $3.67 \pm 1.69$ & $1.63 \pm 0.70$ & $<0.001$ \\
\hline Basal rotation $\left(^{\circ}\right)$ & $-4.14 \pm 1.04$ & $-3.08 \pm 1.12$ & $<0.001$ \\
\hline Twist $\left(^{\circ}\right)$ & $7.81 \pm 2.12$ & $4.71 \pm 1.22$ & $<0.001$ \\
\hline
\end{tabular}

Data are expressed as mean \pm standard deviation

Abbreviations: $L V$ left ventricular, $E$ mitral inflow early diastolic velocity, $A$ mitral inflow late diastolic velocity, $e^{\prime}$ mitral annular early diastolic velocity, $L V E F$ left ventricular ejection fraction, GLS global longitudinal strain, GCS global circumferential strain, GRS global radial strain 


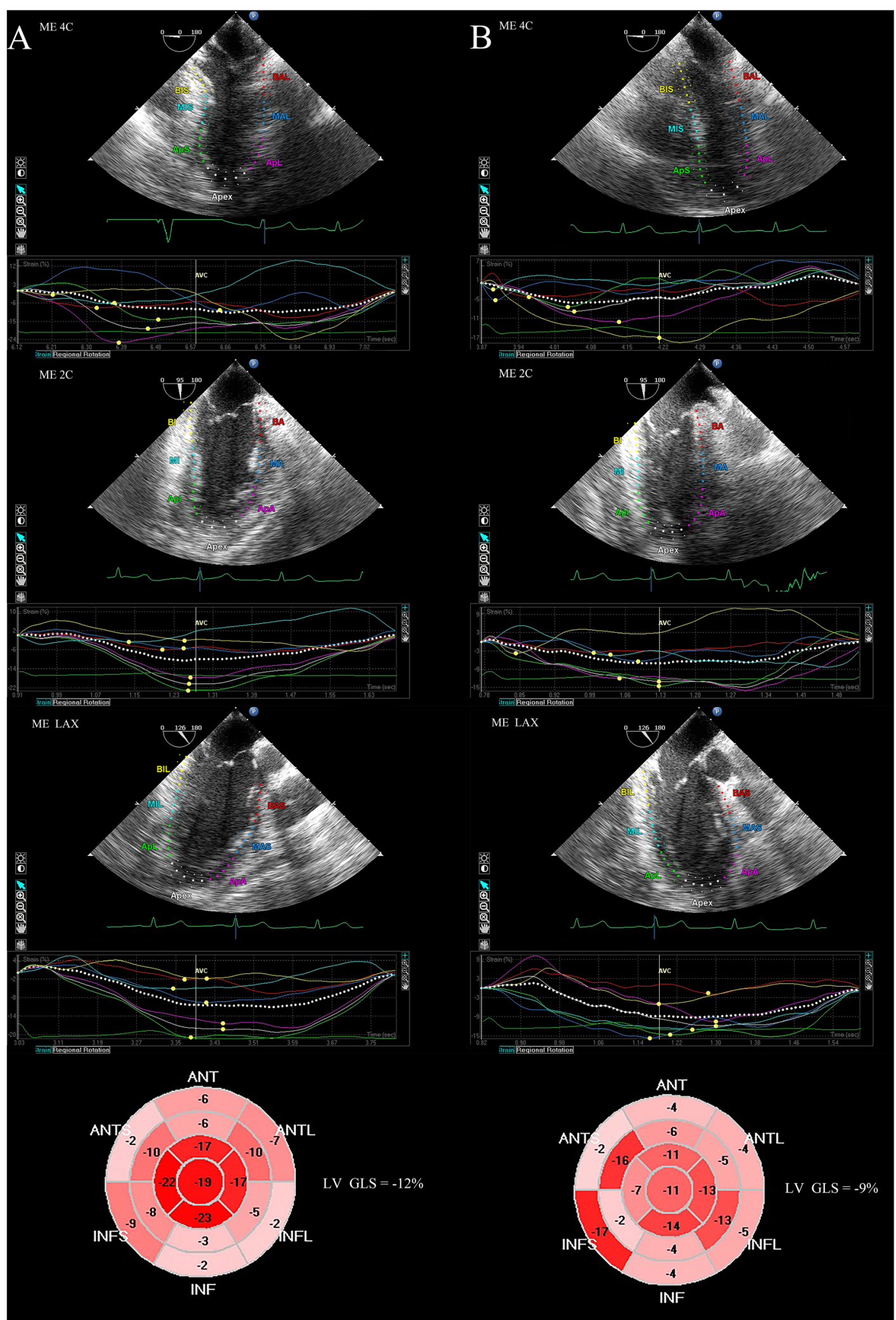

Fig. 2 Measurement of longitudinal strain in ME 4C, ME 2C, and ME LAX view before (a) and after (b) pericardial incision in a case with ischemic cardiomyopathy. This patient had three vessel coronary artery lesions with chronic total occlusion in left circumflex artery. ME 4C, mid-esophageal 4-chamber; ME 2C, mid-esophageal 2-chamber; ME LAX, mid-esophageal long-axis; LV, left ventricular; GLS, global longitudinal strain 
Table 4 Changes in RV morphology and systolic function before and after pericardial incision

\begin{tabular}{lllr}
\hline Parameter & Before pericardial incision $(n=27)$ & After pericardial incision $(n=27)$ & $P$-value \\
\hline RV basal diameter $(\mathrm{mm})$ & $33.89 \pm 3.15$ & $35.37 \pm 3.97$ & 0.11 \\
RV mid-cavity transversal diameter $(\mathrm{mm})$ & $28.59 \pm 2.89$ & $30.44 \pm 3.25$ & $<\mathbf{0 . 0 0 1}$ \\
RV longitudinal diameter $(\mathrm{mm})$ & $59.89 \pm 7.09$ & $59.22 \pm 8.59$ & 0.54 \\
RV sphericity index $(\mathrm{mm})$ & $2.11 \pm 0.29$ & $1.96 \pm 0.31$ & $\mathbf{0 . 0 3}$ \\
RV end-diastolic area $\left(\mathrm{cm}^{2}\right)$ & $13.83 \pm 1.56$ & $13.88 \pm 2.51$ & 0.88 \\
RV end-systolic area $\left(\mathrm{cm}^{2}\right)$ & $7.76 \pm 1.09$ & $7.88 \pm 1.64$ & 0.68 \\
RV fractional area change $(\%)$ & $43.78 \pm 5.39$ & $43.00 \pm 7.47$ & 0.60 \\
\hline
\end{tabular}

Data are expressed as a mean \pm standard deviation

Abbreviations: $R V$ right ventricular

reported the presence of decreased RV systolic function after pericardial incision even with reclosing the pericardium with a continuous suture in different surgical approach and cardioplegia type. The possible mechanisms of decreased RV function after cardiac surgery may be related to the cardiopulmonary bypass use, pericardial adhesions, modality of cardioplegia delivery and pericardial incision, and so on [18], and its clear-cut mechanisms were warranted to be further addressed in the future study.

To date, the existing researches has mainly focused on the influences of pericardial incision on RV. However, only a few studies have researched the effect of the pericardium on LV morphology and systolic function. Tanaka et al. [19] reported that congenital pericardial defects caused depressed apical and basal rotation, and consequently, LV twist was reduced. A canine experiment also showed that twist was reduced after pericardial opening and restored after suturing the pericardium, which suggests the importance of the pericardium in sustaining LV twist [20]. It is still unclear whether pericardial incision could affect LV morphology and systolic function during CABG.

Our study revealed the change of LV morphology from an ellipsoid to sphere after pericardial incision in the patients with CABG, as well as the reduced LV global longitudinal and circumferential strain, reduced twist and increased global radial strain. In the normal heart, pericardial incision may lead to the change of LV preload, filling pressure, and blood pressure [21]. However, these responses may not be so evident in the heart with severe myocardial damage caused by the stenosis or occlusion of coronary artery. Although our results showed the subtle changes between before and after pericardial incision in CVP, SBP, DBP, MAP, and HR with invasive methods, as well as LV filling pressure by noninvasive echocardiography in the patients with CABG, there were no significant differences for all of them. Therefore, we infered that the mechanisms underlying the change of LV morphology from an ellipsoid to a sphere and LV contractile pattern might be mainly attributed to the physical release of pericardial constraint. Maybe, the change of pressure was another pathophysiological mechanism; however, these speculations should be further verified in the future study.

The LV myocardium is made up by the threedimensional arrangement of the myocardial cells, which are supported loosely within a continuous matrix of fibrous tissue. Groups of myocytes are surrounded by condensations of the endomysial weave, thus forming the perimysium, which aggregates a meshwork of myocytes into the so-called myofibers [22, 23]. For describing the global arrangement, most studies have depicted LV myocardium as a transmural continuum which changes continuously from a right-handed helical subendocardium to a left-handed helical subepicardium with the mid-myocardium has a circumferential orientation $[24,25]$. The unique structure of myofibers results in

Table 5 Intra-observer and inter-observer agreement analyses of global strain and rotation

\begin{tabular}{lllll}
\hline Parameter & \multicolumn{2}{l}{ Intra-observer agreement analysis } & & \multicolumn{2}{l}{ Inter-observer agreement analysis } \\
\cline { 2 - 3 } & Bias & $95 \%$ LOA & Bias & . \\
\hline GLS & -0.17 & $-2.94-2.60$ & -0.21 & $-3.08-2.65$ \\
GCS & 0.22 & $-3.02-3.47$ & -0.36 & $-6.02-5.29$ \\
GRS & 0.19 & $-3.72-4.10$ & 0.24 & $-3.74-4.23$ \\
BR & 0.33 & $-2.56-3.21$ & 0.44 & $-2.52-3.41$ \\
AR & 0.31 & $-2.63-3.26$ & 0.55 & $-2.93-4.04$ \\
\hline
\end{tabular}

Abbreviations: LOA limits of agreement, GLS global longitudinal strain, GCS global circumferential strain, GRS global radial strain, GRS global radial strain, $B R$ basal rotation, $A R$ apical rotation 
complicated myocardial motion during systole, and speckle tracking-derived strain could be used to evaluate ventricular systolic function by detecting myocardial deformation in longitudinal, circumferential, radial direction and wringing from base to apex [26].

Deformation parameters change in different directions during the progression of myocardial disease, however, its instantaneous change in this investigation could not be attributed to this. The paradoxical phenomenon in our study that decreased longitudinal and circumferential shortening with preserved ejection fraction is commonly seen in patients with hypertension [27-29]. As the afterload increased, longitudinal and circumferential shortening decreased while the wall thickened as a compensation allowing a preserved ejection fraction. However, there was no significant hemodynamic change immediately after pericardial incision in our study, hence we speculated that the change in myocardial contractile pattern may mainly result from the physical release of pericardial constraint.

Left ventricular ejection fraction is determined by both myocardial strain and wall thickness, which can increase with the increased strain and wall thickness, and even if the strain decreases, it could keep constant because of increased wall thickness [30-32]. Wall thickness is determined by end-diastolic wall thickness and radial thickening (ie radial strain), it has a substantial influence on ejection fraction: a $1 \mathrm{~cm}$ increase in thickness increased ejection fraction by approximately 13 percentage points $[31,32]$. Sheet dynamic and sheet geometry between adjacent myocytes and matrix coupling are crucial for LV wall thickening and dynamics, regional ventricular wall thickening also reflects changes in cardiac fiber and sheet structure during contraction [33, 34]. The present study revealed the immediate changes of LV morphology and deformation but preserved LVEF after pericardial incision, which may indicate that LVEF may be more reliable than GLS to immediately evaluate LV systolic function after pericardial incision for cardiac anesthesiologists.

We could not provide a definite mechanism for the change in contraction pattern in our study, we speculated that the variations in sheet dynamic and geometry caused by the changes in the arrangement of myocytes due to lack of pericardial constraints may play a potential role. Although we did not find significant correlation between wall thickness and ejection fraction, we found the decreased circumferential strain was corelated with the increased radial strain. Therefore, we speculated that the increased radial strain may offset the reduction in longitudinal and circumferential shortening and twisting, allowing for an unchanged ejection fraction.

LV global longitudinal strain as a valuable parameter of LV systolic function has been used in clinical application with a better reproducibility, and it could be a predictor of prognosis and therapeutic effect in patients after CABG [1-4, 35, 36]. In this study, a significant reduction of global longitudinal strain was found in 17 patients immediately after pericardial incision. The SYNTAX score of these 17 patients was significantly lower than that of the other 10 patients, probably because patients with a lower SYNTAX score may have few coronary lesions and more surviving myocardia with better movement; therefore, they may be more susceptible to pericardial incision than patients with a higher SYNTAX score.

Transesophageal 2D STE was used to evaluate LV systolic function during CABG in our study, which showed a high degree of intra-observer and inter-observer agreement. Intraoperative TEE is one of the cornerstones for evaluating immediate changes in myocardial function and helps provide critical information during cardiac surgery. Myocardial strain imaging derived from speckle tracking using TEE is a feasible, reproducible method for assessing LV deformation, which has good agreement with transthoracic strain imaging [37-40].

In the present study, LV morphology and systolic function were investigated only immediately after pericardial incision, and a long-term follow-up was not performed to assess whether any aspect of recovery of contractile patterns would occur because we could not eliminate the interference of myocardial revascularization after CABG. However, the depressed RV systolic function after pericardial incision did not recover within 1 month after CABG in patients without interference of the right coronary artery, [7] suggesting that the effect of pericardial incision on RV systolic function may have persisted. Gozdzik A et al. in their study, observed that global longitudinal strain was still reduced 2 years after CABG [41]. Thus, we speculate that the altered LV morphology and contractile pattern may also persist after CABG, and a well-designed animal experiment should be performed in the future.

\section{Study limitations}

This study has several limitations. First, the correlation between the lower SYNTAX score and the reduction of GLS $>15 \%$ was analyzed based on the limited sample size in the present study. Therefore, a further study with adequate samples from multicenter should be designed to verify these findings. In addition, the invasive LV filling pressure and pulmonary capillary wedge pressure were unable to be obtained during the off-pump beating heart CABG, which may provide the pathophysiological basis for LV modification. However, we provided the LV diastolic indices by noninvasive echocardiography, such as mitral E, mitral A, E/A, septal e', lateral e' and average $\mathrm{E} / \mathrm{e}^{\prime}$, and tricuspid regurgitation velocity, which can 
indirectly reflect the LV filling pressure. Furthermore, we measured the tricuspid regurgitation velocity using ME $4 \mathrm{C}$, and its value may be influenced by the angle of ultrasound beams and may be different from that measured by TTE; however, the present study highlighted its change after pericardial incision and the difference may not influence the research objective. Moreover, it is also worth mentioning that we obtained the results of this work with the Qlab software, which was originally developed for transthoracic images. The absolute values of strain and rotation in the present study may not be identical to the values by transthoracic echocardiography. Currently, there are no recognized standards for the definition of a reduction in LV global systolic function using GLS. We referred to the standard on cancer therapy from the American Society of Echocardiography, which recommended that a reduction in GLS >15\% from baseline is very likely to be abnormal during chemotherapy. The results should be further analyzed using special standards in the future.

\section{Conclusions}

Pericardial incision immediately transformed LV morphology from a prolate spheroid to a sphere during CABG, the LV contractile pattern changed with a decrease in longitudinal and circumferential shortening and twisting, and radial thickening increased despite an unchanged ejection fraction. The altered global longitudinal strain resulting from pericardial incision should be taken into account when evaluating LV systolic function in patients after CABG, especially in patients with a lower SYNTAX score.

\section{Abbreviations}

LV: Left ventricular; RV: Right ventricular; TEE: Transesophageal echocardiography; 2D STE: Two-dimensional speckle tracking echocardiography; CABG: Coronary artery bypass graft; LVEF: Left ventricular ejection fraction; GLS: Global longitudinal strain; GCS: Global circumferential strain; GRS: Global radial strain; ME 4C: Mid esophageal 4-chamber view; ME 2C: Mid esophageal 2-chamber view; ME LAX: Mid esophageal long-axis view; TGB: Transgastric basal short-axis view; TGM: Transgastric mid-papillary short-axis view; TGA: Transgastric apical short-axis view

\section{Acknowledgements}

Not applicable.

\section{Authors' contributions}

LTZ observed indicators, analyzed the data, wrote the manuscript and interpreted the data. LL, PPM, YHW and ML performed the experiment. JY analyzed the data. CYM and TXG designed the study and revised the manuscript. All authors read and approved the final manuscript.

\section{Funding}

This study was supported by the National Natural Science Foundation of China (grant number 81871373).

\section{Availability of data and materials}

The datasets used and/or analyzed during the current study are available from the corresponding author on reasonable request.
Ethics approval and consent to participate

The study protocol was approved by the Ethics Committee of the China Medical University. Informed consent was obtained from all individual participants included in the study.

\section{Consent for publication}

Not applicable.

\section{Competing interests}

The authors declare that they have no competing interests.

Received: 9 January 2020 Accepted: 21 June 2020

Published online: 21 July 2020

\section{References}

1. Lang RM, Badano LP, Mor-Avi V, Afilalo J, Armstrong A, Ernande L, Flachskampf FA, Foster E, Goldstein SA, Kuznetsova T, et al. Recommendations for cardiac chamber quantification by echocardiography in adults: an update from the American Society of Echocardiography and the European Association of Cardiovascular Imaging. J Am Soc Echocardiogr. 2015;28(1):1-39 e14.

2. Ternacle J, Berry M, Alonso E, Kloeckner M, Couetil JP, Rande JL, Gueret P, Monin JL, Lim P. Incremental value of global longitudinal strain for predicting early outcome after cardiac surgery. Eur Heart J Cardiovasc Imaging. 2013;14(1):77-84.

3. Jha AK, Malik V, Gharde P, Chauhan S, Kiran U, Hote MP. Echocardiographic predictors of immediate postoperative outcomes in patients with severe left ventricular systolic dysfunction undergoing on-pump coronary artery bypass grafting. J Cardiothorac Vasc Anesth. 2017;31(1):184-90.

4. Yin ZY, Li XF, Tu YF, Dong DD, Zhao DL, Shen B. Speckle-tracking imaging to monitor myocardial function after coronary artery bypass graft surgery. J Ultrasound Med. 2013;32(11):1951-6.

5. Duncan AE, Alfirevic A, Sessler DI, Popovic ZB, Thomas JD. Perioperative assessment of myocardial deformation. Anesth Analg. 2014;118(3):525-44.

6. Zhang K, Sheu R, Zimmerman NM, Alfirevic A, Sale S, Gillinov AM, Duncan AE. A comparison of global longitudinal, circumferential, and radial strain to predict outcomes after cardiac surgery. J Cardiothorac Vasc Anesth. 2019; 33(5):1315-22

7. Unsworth B, Casula RP, Kyriacou AA, Yadav H, Chukwuemeka A, Cherian A, Stanbridge Rde L, Athanasiou T, Mayet J, Francis DP. The right ventricular annular velocity reduction caused by coronary artery bypass graft surgery occurs at the moment of pericardial incision. Am Heart J. 2010;159(2):314-22.

8. Sianos GMM, Kappetein AP, Morice MC, Colombo A, Dawkins K, van den Brand M, Van Dyck N, Russell ME, Mohr FW, Serruys PW. The SYNTAX score: an angiographic tool grading the complexity of coronary artery disease. Eurolntervention. 2005;1 (Aug):219-27.

9. Hahn RT, Abraham T, Adams MS, Bruce CJ, Glas KE, Lang RM, Reeves ST, Shanewise JS, Siu SC, Stewart W, et al. Guidelines for performing a comprehensive transesophageal echocardiographic examination: recommendations from the American Society of Echocardiography and the Society of Cardiovascular Anesthesiologists. J Am Soc Echocardiogr. 2013; 26(9):921-64.

10. Kim HK, Kim YJ, Park JS, Kim KH, Kim KB, Ahn H, Sohn DW, Oh BH, Park YB, Choi YS. Determinants of the severity of functional tricuspid regurgitation. Am J Cardiol. 2006:98(2):236-42.

11. Plana JC, Galderisi M, Barac A, Ewer MS, Ky B, Scherrer-Crosbie M, Ganame J, Sebag IA, Agler DA, Badano LP, et al. Expert consensus for multimodality imaging evaluation of adult patients during and after cancer therapy: a report from the American Society of Echocardiography and the European Association of Cardiovascular Imaging. J Am Soc Echocardiogr. 2014;27(9): 911-39.

12. Vogiatzidis K, Zarogiannis SG, Aidonidis I, Solenov El, Molyvdas PA, Gourgoulianis Kl, Hatzoglou C. Physiology of pericardial fluid production and drainage. Front Physiol. 2015;6:62

13. Klein AL, Abbara S, Agler DA, Appleton CP, Asher CR, Hoit B, Hung J, Garcia MJ, Kronzon I, Oh JK, et al. American Society of Echocardiography clinical recommendations for multimodality cardiovascular imaging of patients with pericardial disease: endorsed by the Society for Cardiovascular Magnetic Resonance and Society of cardiovascular computed tomography. J Am Soc Echocardiogr. 2013;26(9):965-1012 e15.

14. Shabetai R. Pericardial and cardiac pressure. Circulation. 1988;77(1):1-5. 
15. Rosner A, Avenarius D, Malm S, lqbal A, Schirmer H, Bijnens B, Myrme $T$. Changes in right ventricular shape and deformation following coronary artery bypass surgery-insights from echocardiography with strain rate and magnetic resonance imaging. Echocardiography. 2015; 32(12):1809-20.

16. Unsworth B, Casula RP, Yadav H, Baruah R, Hughes AD, Mayet J, Francis DP. Contrasting effect of different cardiothoracic operations on echocardiographic right ventricular long axis velocities, and implications for interpretation of post-operative values. Int J Cardiol. 2013;165(1):151-60.

17. Raina A, Vaidya A, Gertz ZM, Susan C, Forfia PR. Marked changes in right ventricular contractile pattern after cardiothoracic surgery: implications for post-surgical assessment of right ventricular function. J Heart Lung Transplant. 2013:32(8):777-83.

18. Zanobini M, Loardi C, Poggio P, Tamborini G, Veglia F, Di Minno A, Myasoedova V, Mammana LF, Biondi R, Pepi M, et al. The impact of pericardial approach and myocardial protection onto postoperative right ventricle function reduction. J Cardiothorac Surg. 2018;13(1):55.

19. Tanaka H, Oishi $Y$, Mizuguchi $Y$, Miyoshi H, Ishimoto T, Nagase N, Yamada H, Oki T. Contribution of the pericardium to left ventricular torsion and regional myocardial function in patients with total absence of the left pericardium. J Am Soc Echocardiogr. 2008;21(3):268-74

20. Chang SA, Kim HK, Kim YJ, Cho GY, Oh S, Sohn DW. Role of pericardium in the maintenance of left ventricular twist. Heart. 2010;96(10):785-90.

21. Weber KT, Janicki JS, Shroff S, Fishman AP. Contractile mechanics and interaction of the right and left ventricles. Am J Cardiol. 1981;47(3):686-95.

22. Sengupta PP, Korinek J, Belohlavek M, Narula J, Vannan MA, Jahangir A, Khandheria BK. Left ventricular structure and function: basic science for cardiac imaging. J Am Coll Cardiol. 2006;48(10):1988-2001.

23. Anderson RH, Ho SY, Redmann K, Sanchez-Quintana D, Lunkenheimer PP. The anatomical arrangement of the myocardial cells making up the ventricular mass. Eur J Cardiothorac Surg. 2005;28(4):517-25.

24. Buckberg GD, Clemente C, Cox JL, Coghlan HC, Castella M, Torrent-Guasp F, Gharib M. The structure and function of the helical heart and its buttress wrapping. IV. Concepts of dynamic function from the Normal macroscopic helical structure. Semin Thorac Cardiovasc Surg. 2001;13(4):342-57.

25. Thomas JD, Popovic ZB. Assessment of left ventricular function by cardiac ultrasound. J Am Coll Cardiol. 2006;48(10):2012-25.

26. Geyer H, Caracciolo G, Abe H, Wilansky S, Carerj S, Gentile F, Nesser HJ, Khandheria B, Narula J, Sengupta PP. Assessment of myocardial mechanics using speckle tracking echocardiography: fundamentals and clinical applications. J Am Soc Echocardiogr. 2010;23(4):351-69 quiz 453-5.

27. Rodrigues JC, Rohan S, Dastidar AG, Trickey A, Szantho G, Ratcliffe LE, Burchell AE, Hart EC, Bucciarelli-Ducci C, Hamilton MC, et al. The relationship between left Ventricular Wall thickness, myocardial shortening, and ejection fraction in hypertensive heart disease: insights from cardiac magnetic resonance imaging. J Clin Hypertens (Greenwich). 2016;18(11):1119-27.

28. Mizuguchi Y, Oishi Y, Miyoshi H, luchi A, Nagase N, Oki T. Concentric left ventricular hypertrophy brings deterioration of systolic longitudinal, circumferential, and radial myocardial deformation in hypertensive patients with preserved left ventricular pump function. J Cardiol. 2010;55(1):23-33.

29. Palmon LC, Reichek N, Yeon SB, Clark NR, Brownson D, Hoffman E, Axel L. Intramural myocardial shortening in hypertensive left ventricular hypertrophy with normal pump function. Circulation. 1994;89(1):122-31.

30. Maclver $\mathrm{DH}$, Adeniran I, Zhang $\mathrm{H}$. Left ventricular ejection fraction is determined by both global myocardial strain and wall thickness. Int J Cardiol Heart Vasc. 2015;7:113-8.

31. Stokke TM, Hasselberg NE, Smedsrud MK, Sarvari SI, Haugaa KH, Smiseth OA, Edvardsen T, Remme EW. Geometry as a confounder when assessing ventricular systolic function: comparison between ejection fraction and strain. J Am Coll Cardiol. 2017;70(8):942-54.

32. Maciver $\mathrm{DH}$. A new method for quantification of left ventricular systolic function using a corrected ejection fraction. Eur J Echocardiography. 2011; 12(3):228-34.

33. Cheng A, Nguyen TC, Malinowski M, Daughters GT, Miller DC, Ingels NB Jr. Heterogeneity of left ventricular wall thickening mechanisms. Circulation. 2008;118(7):713-21.

34. Chen J, Liu W, Zhang H, Lacy L, Yang X, Song SK, Wickline SA, Yu X. Regional ventricular wall thickening reflects changes in cardiac fiber and sheet structure during contraction: quantification with diffusion tensor MRI. Am J Phys Heart Circ Phys. 2005;289(5):H1898-907.
35. Potter E, Marwick TH. Assessment of left ventricular function by echocardiography: the case for routinely adding global longitudinal strain to ejection fraction. JACC Cardiovasc Imaging. 2018;11(2 Pt 1):260-74.

36. Smiseth OA, Torp H, Opdahl A, Haugaa KH, Urheim S. Myocardial strain imaging: how useful is it in clinical decision making? Eur Heart J. 2016; 37(15):1196-207.

37. Marcucci CE, Samad Z, Rivera J, Adams DB, Philips-Bute BG, Mahajan A, Douglas PS, Aronson S, Mackensen GB, Podgoreanu MV, et al. A comparative evaluation of transesophageal and transthoracic echocardiography for measurement of left ventricular systolic strain using speckle tracking. J Cardiothorac Vasc Anesth. 2012;26(1):17-25.

38. Kurt M, Tanboga IH, Isik T, Kaya A, Ekinci M, Bilen E, Can MM, Karakas MF, Bayram E, Aksakal E, et al. Comparison of transthoracic and transesophageal 2-dimensional speckle tracking echocardiography. J Cardiothorac Vasc Anesth. 2012;26(1):26-31.

39. Skubas NJ. Two-dimensional, non-Doppler strain imaging during anesthesia and cardiac surgery. Echocardiography. 2009;26(3):345-53.

40. Kukucka M, Nasseri B, Tscherkaschin A, Mladenow A, Kuppe H, Habazettl H. The feasibility of speckle tracking for intraoperative assessment of regional myocardial function by transesophageal echocardiography. J Cardiothorac Vasc Anesth. 2009;23(4):462-7.

41. Gozdzik A, Letachowicz K, Grajek BB, Plonek T, Obremska M, Jasinski M, Gozdzik W. Application of strain and other echocardiographic parameters in the evaluation of early and long-term clinical outcomes after cardiac surgery revascularization. BMC Cardiovasc Disord. 2019;19(1):189.

\section{Publisher's Note}

Springer Nature remains neutral with regard to jurisdictional claims in published maps and institutional affiliations.
Ready to submit your research? Choose BMC and benefit from:

- fast, convenient online submission

- thorough peer review by experienced researchers in your field

- rapid publication on acceptance

- support for research data, including large and complex data types

- gold Open Access which fosters wider collaboration and increased citations

- maximum visibility for your research: over $100 \mathrm{M}$ website views per year

At BMC, research is always in progress.

Learn more biomedcentral.com/submissions 